\title{
Attitudes in the motivational sphere and Change readiness of university students
}

\author{
Galina Kozhukhar ${ }^{1}$, Alla Belousova ${ }^{2, *}$, and Elena Breus $^{3}$ \\ ${ }^{1}$ Moscow State University of Psychology and Education, 127051, Sretenka, 29 Moscow, Russian \\ Federation \\ ${ }^{2}$ Don State Technical University, 344003, Gagarin Sq. 1, Rostov-on-Don, Russian Federation \\ ${ }^{3}$ Southern Federal University, 344006, 105/42 Bolshaya Sadovaya Str., Rostov-on-Don, Russian \\ Federation
}

\begin{abstract}
The article examines the interrelations between sociopsychological attitudes in the motivational sphere and change readiness of students of the liberal arts profile university. Change readiness is understood as an important component of innovative activity. Also, attitudes in the motivational sphere were identified as predictors of change readiness. The following methods were used: O.F. Potemkina's diagnostics of socio-psychological attitudes of personality and PCRS methodology "Personal change readiness in the context of "expectation" phenomenon study (Rollnick, Heather, Gold, Hall). The study involved 80 university students, aged 18 to 23 . The results describe the interrelations between different socio-psychological attitudes and the components of change readiness, and also show which attitudes act as predictors of the integral indicator of change readiness. The reliability of the data is confirmed by the use of a set of mathematical statistics methods.
\end{abstract}

\section{Introduction}

In adolescence, such processes as the development of the social maturity of the individual, its movement towards a conscious and responsible life, and the continuation of professional identity take place. Modern society presents new challenges to the individual due to social changes: the need to introduce innovations affects all spheres of life. Life itself becomes innovation. These processes largely depend on the socio-economic conditions of society, on upbringing, education at school and university, on the value orientations of the family and on the personal characteristics of the people themselves.

An understanding of innovations in various fields of activity, in particular, in education, is proposed within the framework of different approaches (systemic, systemicanthropological, semantic and others), the components of innovative activity, its conditions and factors have also been studied [1-16]. The role of collaborative thinking activity in the organization and implementation of innovations is shown, which is impossible without appropriate attitudes and motives [3].

*Corresponding author:belousovaak@gmail.com 
Innovations are essential for human society to develop. The innovation process consists of two phases that appear in a cyclic nature: the generation of ideas and, as a matter of fact, the introduction of innovations. To allow these phases to function optimally, both individuals and groups must work in an environment that is best for innovations introduction. Some authors argue that there are many factors that positively influence both individual and group innovations (for example, self-confidence, self-efficacy, autonomy, anticipation of innovations from the leader, perception of a safe environment, clarity of goals, diversity and support of innovations). There are also many factors that have a positive effect on innovations at one level, but reduce them on another (individualism, openness to experience, pressure from external requirements, time and financial resources and reflexivity) $[4,5]$.

We identified the consideration of the value orientations of the readiness of young people in the metropolitan city to accept innovations in modern education from the point of view of the axiological approach. The possibilities of innovation in ethical education [6], the role of eco-innovation in organizations that stimulate the cooperation [7] were also studied.

In this regard, the motivational indicator of the innovative readiness of a university teacher acts as the main one, it ensures the rejection of old stereotypes of pedagogical activity, attitudes, habits, it also allows to improve the level of readiness of the teaching staff to introduce the interactive forms of education. But if you do not develop a readiness to changes among university students, one can hardly expect innovative activity in the future professional activity, since educational institutions are an important source of innovations [8-10].

This article is devoted to the study of the interrelations between socio-psychological attitudes and change readiness, as well as to the identification of attitudes that allow to predict the level of change readiness as an integral indicator. Change readiness is one of the components that largely ensures the adoption and implementation of innovations. Identity formation of a person depends to a large extent on socio-psychological attitudes. At the same time, in the modern world, young people are exposed to different types of stress, including fear of changes and a lack of readiness to changes in social and other spheres of life. Speaking about changes, it is important to mention that the personality of students as future professionals needs successful adaptation based on the readiness to innovations.

\section{Research methods}

The main goal of the study is to create a standard model to explain the interrelations between characteristics, and to identify predictors of the integral indicator of change readiness.

The following psychodiagnostic methods were used:

1. O. F. Potemkina's Diagnostics of Socio-psychological Attitudes of Personality.

2. PCRS methodology - "Personal change readiness in the context of "expectation" phenomenon study (Rollnick, Heather, Gold, Hallier).

Allow us to give a description of the methodology.

1. O. F. Potemkina's Diagnostics of Socio-psychological Attitudes of Personality [11].

The methodology for diagnosing social and psychological attitudes of a person was proposed by O.F. Potemkina. This survey allows you to study the motivational-need sphere and determine what is more important for a person: altruism or egoism, process or result; what is of greater importance - freedom or power, labour or money.

The methodology consists of 80 questions: 40 questions are aimed at identifying the degree of manifestation of socio-psychological attitudes towards "altruism - egoism", 
"process - result", 40 questions are aimed at identifying the degree of manifestation of socio-psychological attitudes "freedom - power", "labour - money".

2. Personal change readiness in the context of "expectation" phenomenon study (PCRS). This methodology was proposed and developed by Canadian scientists Rollnik, Heather, Gold and Hall (PCRS) [12].

The methodology is especially effective when dealing with stressful situations arising in connection with innovations, as few people manage to fully cope with changes. Understanding the characteristics of resisting the changes helps people to protect themselves from stress in the situations in which they are most vulnerable.

The number of points for each of the seven scales is calculated, as well as the total score for all scales. The methodology includes seven scales that measure the personal change readiness. PCRS scales: 1) passion; 2) resourcefulness; 3) optimism; 4) adventurousness; 5) adaptability; 6) confidence is based on believing in oneself, in one's dignity and in one's own strengths, in the fact that everything is possible, it only takes your desire; 7) tolerance for ambiguity.

Sample: the study was conducted on the basis of Moscow and Rostov-on-Don. The study involved young people studying in universities aged 18 to 23 . A total of 80 people: $64(80 \%)$ girls and 16 boys $(20 \%)$.

The SPSS v.23 was used for statistical data processing. (descriptive statistics, correlation and regression analysis, automatic linear modeling).

\section{Study results and their discussion.}

\subsection{Descriptive statistics}

The average age of the subjects participating in the study was $19.56, \mathrm{SD}=0.98$. By this age, a person should have already formed social attitudes, world views and objectives for the future.

Let us consider the results obtained:

It was found that the hierarchy of attitudes among students is expressed in terms of the degree of significance in the following way: freedom, process, result, altruism, labour, egoism, power, money.

4 out of 7 are clearly expressed - these are attitudes towards "Freedom" (6.50), "Process" (6.19), "Result" (5.53) and "Altruism" (5.41). The least expressed were attitudes towards "Labour" (3.88), "Egoism" (3.78), "Power" (3.33) and "Money" (2.46).

These value dominants, on the one hand, do not contradict the readiness to participate in educational innovations, on the other hand, they reflect a passive consumerist position in relation to the innovation process [5]. It follows that we can conclude that today's young people are more focused on unlimitedness, on the absence of any "framework" around them, giving themselves away to any business, while having freedom of action, fantasy and time. At the same time, they prefer to be immersed in their business, while working for the process and the result of their business. Labour for them should be, first of all, interesting and unrestricted. The activity and the result of their labour are important to them. We can say that such people are reliable. Altruistic values are of great importance. Students are ready to selflessly help to take on the benefits of other people, to help and respond with empathy to requests for help.

According to the methodology of studying the change readiness, if the sum is less than 21 points on each scale, then this indicates a low level of development of the measured characteristic. The mean, optimal level of characteristic development is within the range 
from 22 to 26 points. A total of over 27 points is assessed as a high level of the measured characteristic development.

If we analyze the mean value of each scale, it becomes clear to us that the indicator of none of the scales falls within the optimal and highest value of the measured characteristics. In other words, now young people do not cope well with stressful situations and experience difficulties when encountering innovations in life. Indeed, resistance to the introduction of innovations is also observed among teachers; therefore, it is important to carry out goaloriented activity aimed at increasing the psychological readiness to innovative activity and its components, which will reduce the resistance of both teachers and students to innovations.

Nevertheless, for both boys and girls such scales as "resourcefulness" (20.18), "confidence" (18.76), “optimism" (18.36) and "passion" (18.18) are identified. "Adaptability" (14.85), "adventurousness" (14.15) and "tolerance for ambiguity" (13.38) are expressed at a low level. Let's consider each scale in more detail below.

\subsection{The interrelation between socio-psychological attitudes and change readiness in students}

Next, let us consider the most important, in the context of this work, correlations at a significance level of $\mathrm{p} \leq 0.01(* *)$ and $\mathrm{p} \leq 0.05(*)$.

Boys in our sample are less inclined to show passion $\left(\mathrm{r}=-0.225^{*}\right)$ and confidence $(\mathrm{r}=$ $\left.0.337^{* *}\right)$, while girls are more adaptive $(\mathrm{r}=0.253 *)$. As for socio-psychological attitudes, there was a tendency among young men to manifest egoism $\left(\mathrm{r}=-0.317^{* *}\right)$, while girls showed a greater orientation towards the process $(\mathrm{r}=-0.227 *)$ and manifestation of altruism $\left(\mathrm{r}=0.386^{* *}\right)$. We are talking about trends, since the sample is not sex-balanced, but, at the same time, it reflects, in general, the objective realities of the ratio of boys and girls at modern liberal arts faculties.

Moreover, the older the students are, the more optimistic they are $\left(\mathrm{r}=0.310^{* *}\right)$. Therefore, we can say that young people, when facing the changes in their lives and innovations, are generally oriented towards success, feel hope for the best and fixate on solving problems.

A total of 19 interrelations were found between the attitudes in the motivational sphere and change readiness, which seems to indicate a strong connection between these phenomena.

The interrelations between the socio-psychological attitudes and personal change readiness in students were manifested in the following way.

An increased focus on the process leads to an increase in adaptability $\left(\mathrm{r}=0.306^{* *}\right)$ and tolerance for ambiguity $(\mathrm{r}=0.275 *)$. An increase in orientation towards the results is directly related to an increase in passion $\left(\mathrm{r}=0.392^{* *}\right)$, resourcefulness $(\mathrm{r}=0.360 * *)$, and confidence $\left(r=0.226^{*}\right)$. Surprisingly, an increase in altruism is inversely related to confidence $\left(\mathrm{r}=-0.320^{* *}\right)$, while an increase in egoism is positively related to this characteristic $(\mathrm{r}=0 . .248 *)$. The higher the attitude towards work, the more passionately ( $\mathrm{r}$ $\left.=0.338^{* *}\right)$ and resourcefully $\left(\mathrm{r}=0.335^{* *}\right)$ students manifest themselves in activity. The attitude towards money reduces optimism $\left(\mathrm{r}=-0.328^{*}\right)$ and adventurousness $(\mathrm{r}=0.359$ $* *)$. The role of freedom is positively related to resourcefulness $\left(\mathrm{r}=0.318^{* *}\right)$, and confidence $\left(\mathrm{r}=0.310^{* *}\right)$. While the attitude towards power increases simultaneously with resourcefulness $\left(\mathrm{r}=0.367^{* *}\right)$ and confidence $\left(\mathrm{r}=0.594^{* *}\right)$, but decreases in the case of an increase in the orientation towards adventurousness $(\mathrm{r}=-0.355 * *)$. An integral indicator of change readiness with attitudes towards results $\left(\mathrm{r}=0.224^{*}\right)$ and labour $(\mathrm{r}=0.232 *)$, and inversely - with a socio-psychological attitude towards money $(r=-0.221 *)$. 
Students who are focused on paying as much time as possible on doing any activity, increase endurance when are faced with changes in life and innovations. They are distinguished by vigorousness and tirelessness, they are reliable, they always reach their goals, and when they are faced with changes and innovations in life they are able to show ingenuity, find a way out of difficult situations, and overcome obstacles that will stand in their way. These students have quick-wittedness, entrepreneurial spirit and ingenuity. An important personal factor is openness to experience [20].

Students for whom unrestrictedness and independence are important, when faced with changes in life and innovations, also show ingenuity, the ability to find a way out of difficult situations.

The students, whose life orientation is associated with increasing their well-being, when faced with changes and innovations in life, will focus not on positive aspects, but on negative ones: they fixate on problems, and not on their solution, have little faith in their success and a positive future. It turns out that students want to increase their prosperity, but when faced with changes in their lives and innovations, they prefer to choose a well-known path to achieve their goals, trying to avoid everything new and follow the "proven" path.

Goal-oriented students who work for results, despite the circumstances, remain selfconfident even when faced with changes in life and innovations. They are aware of their strengths, opportunities and use them.

At the same time, those students who are inclined to help others to the detriment of their own interests, when faced with changes in their lives experience lack of confidence in themselves and their strengths, stop trusting other people.

In general, we can conclude that students, whose life socio-psychological attitudes are aimed at influencing others and their own financial well-being, avoid the new and the unknown when faced with changes in their lives, and achieve goals in proven ways. Also, value orientations towards well-being are marked by a low indicator of hope for success and positive thoughts about the future. At the same time, students who are focused on subordinating others to themselves also show resourcefulness when faced with changes in life and a high belief in themselves and in their own strengths.

\subsection{Socio-psychological attitudes of students as change readiness predictors}

In order to study the influence of independent variables, which were socio-psychological attitudes, on the dependent variable - the integral indicator of change readiness, we used a multiple linear regression analysis (forced inclusion method and step-by-step method).

The results of multiple regression analysis showed that an increase in the integral indicator of change readiness can be predicted in case of an increase in labour motivation (Table 1).

$\mathrm{R}$-squared is the coefficient of determination $\left(\mathrm{R}^{2}=0.06\right)$, allowing us to determine the proportion of variation in one of the variables, which is explained by changes in the other variable. When analyzing the role of labour in change readiness, $\mathrm{R}^{2}=0.06$, i.e. the proportion of variation is explained by the variation of change in motivation to labour by $6 \%$. At the same time, the remaining $94 \%$ are explained by the influence of other factors. The significance of the correlation coefficient was $p=0.038>0.05$. Change readiness acts not only as a mobilization of forces that ensures the achievement of changes, but also as that psychological resource of a person that contributes to the achievement of well-being in life [21].

Table 1. Coefficients for the dependent variable "Integral indicator of change readiness"

\begin{tabular}{|c|c|c|c|}
\hline Model 1 & Beta & $\mathrm{t}$ & Value \\
\hline (Invariable) & & 36.436 & 0.000 \\
\hline Labour & 0.232 & 2.110 & 0.038 \\
\hline
\end{tabular}


Further, using automatic linear modeling (step-by-step method) to determine how much weight attitudes have in influencing the integral indicator of change readiness, we found that only money acted as a negative predictor

The information criterion was 401.598, and the model accuracy was $14.9 \%(\mathrm{t}=-3.166$; significance $\mathrm{p}=0.002$; importance (weight) $=0.489$ ). Thus, the higher the focus on money, the less the students are ready to changes and can be expected to be focused on the innovations introduction.

We also used automatic modeling in order to identify the importance of the contribution made by the components of change readiness to its integral indicator. As a result, an ideal model was obtained in terms of the cumulative effect of predictors: the accuracy was $100 \%$. Passion, optimism, adventurousness were of equal importance (at $p=0.000$ ), which had an equal importance indicator -0.164 . Then, in terms of weight, there were placed confidence (importance $=0.154: \mathrm{p}=0.000$ ), tolerance for ambiguity (importance $=0.137 ; \mathrm{p}=0.000$ ), resourcefulness $\mathrm{p}=0.000$ ), and adaptability (importance $=0.108 ; \mathrm{p}=0.000$ ) was the last most important component. Adaptability in the last place seems logical from the point of view of the fact that innovations imply going beyond the currently available, thereby showing a conditional "maladjustment" to a creative situation. At the same time, studies show that acculturation, in particular, the integration of contrasting cultural ideas, acts as a positive and significant predictor of innovation [13].

Change readiness is directly related to the preference for innovative activity and the general index of psychological readiness to innovative activity. Actually, change readiness is one of the parameters of psychological readiness to innovative activity.

As prospects for future research, it is proposed to identify the role of value orientations and interpersonal relations in connection with the readiness to introduce innovations [14].

It can be concluded that if we motivate students by increasing socio-psychological attitudes towards work, then their level of personal change readiness will increase, they will more easily experience the difficulties they face, and thus we will be able to predict an increase in personal readiness to the innovations introduction. To do this, one can use innovative models of programs for the education system [15], and it is also important to develop entrepreneurial skills [16].

\section{Conclusions}

It became clear that the attitudes towards "Freedom", "Process", "Result", "Altruism" dominate among modern young people. Next were the attitudes towards "Labour", "Egoism", "Power", and only then "Money".

In general, modern students have a weak change readiness, are poorly oriented in unforeseen situations and prefer high uncertainty avoidance. This is confirmed by the low level of expression of these indicators.

Young people with predominant socio-psychological orientation towards results and labour, use the strategy of passion and resourcefulness when faced with changes in their lives. Students who always achieve goals in spite of everything, when faced with changes and innovations in life, experience a rise in energy, are characterized by their efficiency and high endurance.

It was found that students, whose life socio-psychological attitudes are aimed at influencing others and financial well-being, avoid the new and unknown when faced with changes in life, achieve goals in proven ways. Also, value orientations towards well-being are marked by a low indicator of hope for success, positive thoughts about the future. 
Students with a socio-psychological attitude towards results are the most productive and prepared for changes in life, and they are also most fully aware of themselves and their place in the world.

The socio-psychological attitude in the motivational sphere towards labour makes it possible to predict change readiness as one of important components of innovative activity.

The attitude towards money is a predictor of unwillingness to changes, and accordingly, such students find it difficult to cope with changes and difficulties, they are less prepared when innovations are introduced.

Thus, the standard model that allows us to predict a high level of change readiness for our sample includes high motivation to labour with a low level of attitude towards money.

\section{References}

1. V. Cosmin Blândul, Procedia - Social and Behavioral Sciences, 180, 484 - 488 doi: 10.1016/j.sbspro.2015.02.148

2. V. Akberdina, L. Pushkareva, Proceedings of the 4th International Conference on Social, Business, and Academic Leadership (ICSBAL 2019) (2019). doi:10.2991/icsbal-19.2019.3

3. A. Belousova, L. Abrosimova, M. Bogdanova, 11th International Technology, Education and Development Conference, Valencia, Spain. INTED2017 Proceedings, 1915-1921 (2017) doi: 10.21125/inted.2017.0577

4. Beerkens, Bas. Influencing factors in innovation on individual and group level. (2018) URL: https://edepot.wur.nl/458406 (Last accessed 12.05.2020)

5. C. Wu, S. K. Parker, G. De Jong, Journal of Management, 40(6), 1511-1534 (2014) doi: $10.1177 / 0149206311429862$

6. P. Fridrichova, Procedia - Social Behavioral Sciences, 174, 3385-3389 (2015) doi: 10.1016/j.sbspro.2015.01.1008

7. A. Szilagyi, M. Mocan, A. Verniquet, A. Churican, D. Rochat, Procedia - Social and Behavioral Sciences, 238, 475-484 (2018) doi: 10.1016/j.sbspro.2018.04.026

8. M. Keinänen, J. Ursin, K. Nissinen, Studies in Educational Evaluation, 58, 30-36 (2018) doi.org/10.1016/j.stueduc.2018.05.007

9. H. Moona, B. J. Mariadoss , J. L. Johnson, Journal of Business Research, 99, 534-541 (2019) doi: 10.1016/j.jbusres.2017.09.033

10. L. D. Field, Arthroscopy: The Journal of Arthroscopic \& Related Surgery, 36(7), 17811787 (2020) doi: 10.1016/j.arthro.2020.05.029

11. file://C:/Users/user/Downloads/uch00289.pdf S. 178-182. [Russian Edition] (Last accessed 15.05.2020)

12. S. Rollnick, N. Heather, R. Gold, W. Hall, British Journal of addiction, 87(5), 743-754 (1992) doi: 10.1111/j.1360-0443.1992.tb02720.x.I

13. R. Sharif, Educational Research Review, 28, 100287 (2019) doi: 10.1016/j.edurev.2019.100287

14. G. Kozhukhar, A. Belousova, EDULEARN Proceedings, 5791-5796 (2017) doi: 10.21125/edulearn.2017.2311

15. V. Ellis, A. Childs, Teaching and Teacher Education, 77, 276-286 (2019) doi: 10.1016/j.tate.2018.10.020

16. S. J.L. van Wettena, R. Gerardsa, A. de Gripa, Technovation, 96-97, 102131 (2020) doi: 10.1016/j.technovation.2020.102131 